\title{
Peertechz
}



Short Communication

\section{Penetrating keratoplasty for the management of a severe idiopathic lipid keratopathy}

\author{
Eirini Kaisari' ${ }^{1}$ Emmanouil Blavakis ${ }^{1}$ and Georgios \\ Kymionis ${ }^{1,2 *}$ \\ 'Department of Ophthalmology, University of Lausanne, Jules-Gonin Eye Hospital, Fondation Asile des \\ aveugles, Lausanne, Switzerland \\ ${ }^{2}$ Department of Ophthalmology, National and Kapodistrian University of Athens, General Hospital “G. \\ Gennimatas", Athens, Greece
}

Received: 18 August, 2021

Accepted: 06 September, 2021

Published: 07 September, 2021

*Corresponding authors: Georgios Kymionis, MD, PhD, Department of Ophthalmology, University of Lausanne, Jules-Gonin Eye Hospital, Fondation Asile des aveugles 15 Avenue de France, 1002, Lausanne, Switzerland, Tel: +41 7933322 59; E-mail: irenekaisari@gmail.com, gkymionis@gmail.com

https://www.peertechzpublications.com

Check for updates
An 83-year-old female presented with progressive bilateral lipid keratopathy (LK) during the last 12 years. There was no history of previous ocular disease or trauma. Slit lamp examination of the left eye revealed a diffuse LK obscuring the visual axis and a temporal epithelial papillomatous lesion with superficial neovascularization (Figure A), while Best Corrected Visual Acuity (BCVA) was 20/200 with eccentric fixation. An uneventful Penetrating Keratoplasty (PKP) combined with excision of the temporal lesion was performed. Pathologic examination was indicative of LK, revealing chronic stromal inflammation including lymphocytes and histiocytes, partially xanthomized and the presence of cholesterol crystals. Two years post-operatively, the corneal graft was clear and BCVA was $20 / 20$ following cataract surgery (Figure B). LK is either idiopathic, typically bilateral, or unilateral secondary to corneal neovascularization due to ocular disease or trauma [1]. Our case illustrates a severe form of idiopathic LK, treated successfully with PKP.

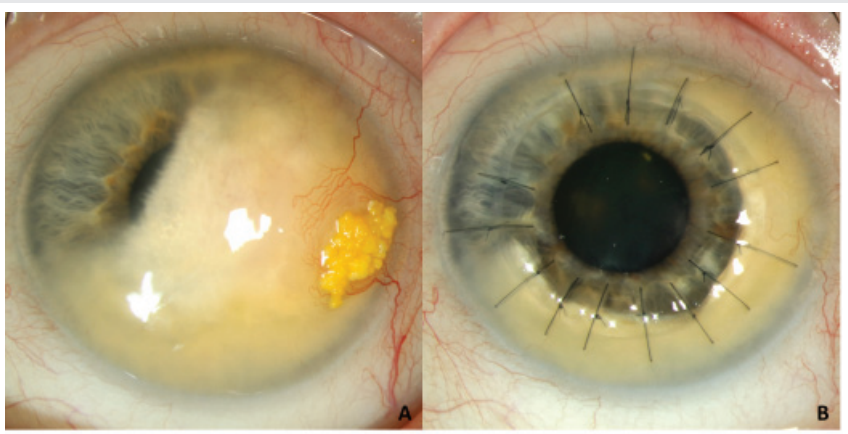

Figure 1: A: Slit lamp examination of the left eye revealed a diffuse LK obscuring the visual axis and a temporal epithelial papillomatous lesion with superficial neovascularization. B. Two years post-operatively, the corneal graft was clear and BCVA was 20/20 following cataract surgery..

\section{References}

1. Hall MN, Moshirfar M, Amin-Javaheri A, Ouano DP, Ronquillo $Y$, et al. (2020) Lipid Keratopathy: A Review of Pathophysiology, Differential Diagnosis, and Management. Ophthalmol Ther 9: 833-852. Link: https://bit.ly/3tk9d9D 